\title{
Influence of the Interfacial Properties on the Stability of Water in Heavy Oil Emulsions in Thermal Recovery Process
}

\author{
Yongtao Sun $\mathbb{D I}^{1,2}$ and Zhaomin $\mathrm{Li} \mathbb{D}^{1}$ \\ ${ }^{1}$ College of Petroleum Engineering, China University of Petroleum (East China), Qingdao, Shandong, China 266580 \\ ${ }^{2}$ China Oilfield Services Limited, CNOOC, Tanggu, Tianjin, China 300459 \\ Correspondence should be addressed to Yongtao Sun; 375267930@qq.com and Zhaomin Li; lizhm@upc.edu.cn
}

Received 17 August 2020; Revised 2 September 2020; Accepted 30 October 2020; Published 18 November 2020

Academic Editor: Guanglong Sheng

Copyright (C) 2020 Yongtao Sun and Zhaomin Li. This is an open access article distributed under the Creative Commons Attribution License, which permits unrestricted use, distribution, and reproduction in any medium, provided the original work is properly cited.

\begin{abstract}
Under the conditions of thermal oil recovery, the heavy oil in a reservoir usually exists in the form of W/O emulsion with high water content, which has significant effect on oil recovery performance. The most important parameter on the stability of W/O emulsion is interfacial properties. Thus, in order to investigate the effect of interfacial properties on the stability of W/O emulsion in a heavy oil reservoir at elevated temperatures, experiments have been conducted to generate various emulsions with variations in the temperature; stirring rate; contents of asphaltene, resin, and wax of the simulated heavy oil; and water salinity based on a target heavy oil reservoir in China. Then, the properties of the W/O emulsions include viscosity, interfacial viscosity (IFV), interfacial tension (IFT), and dehydration rate; the microscopic morphologies are measured as well. The experimental results show evidently stable $\mathrm{W} / \mathrm{O}$ emulsion of heavy oil and water generated in thermal processes due to the stable, thick, and indistinct interface between heavy oil and water, where the active molecules of asphaltene and resin are accumulated. The interface connects the central large droplet and the surrounding small droplets tightly. The results also indicate the size of the central droplet, and the indistinct interface can be enlarged with increasing temperature and increasing stirring rate. Compared to resin, it is noted that the larger asphaltene molecules have stronger connection because of their stronger intermolecular force, larger IFV, and less IFT. At the same time, the stability of W/O emulsion will be strengthened with increasing temperature and stirring rate and gradually weakened with increasing salinity. In conclusion, the stability of water in heavy oil emulsion is mainly related to the large interfacial viscosity of the interface with much more heavy components such as asphaltene and resin compared to thin oil.
\end{abstract}

\section{Introduction}

More than half of the proven oil reserves in the Bohai Oilfield are heavy oil with viscosity over $150 \mathrm{mPa} \cdot \mathrm{s}$, and the depth of the reservoirs usually ranges from $1000 \mathrm{~m}$ to $1500 \mathrm{~m}$. In the past years, the production rates of the heavy oil wells with viscosity of $350 \mathrm{mPa} \cdot \mathrm{s}-1000 \mathrm{mPa} \cdot \mathrm{s}$ were significantly increased by thermal processes, such as cyclic steam stimulation and cyclic steam and gas stimulation, and more than $50 \mathrm{~m}^{3} / \mathrm{d}$ oil production rate was obtained compared to the rate of below $20 \mathrm{~m}^{3} / \mathrm{d}$ by primary cold production.
Simultaneously, stable and viscous heavy oil emulsion was found during the thermal processes.

In fact, heavy oil is inclined to emulsify with water because of its large contents of asphaltene, resin, and wax, and the generation and stability of heavy oil emulsion is mainly related to the properties of the interface between heavy oil and water. As a result, the heavy oil is produced to surface in the form of stable W/O emulsion in thermal recovery processes such as steam injection [1-3]. The emulsification of heavy oil and water usually results in difficulty of water separation and failure of the dewatering equipment 
on the oil production platform in an offshore oilfield [4-7]. Therefore, the principles and impact factors on the stability of W/O emulsion during steam injection processes are significantly important for the evaluation of heavy oil mobility and treatment of produced fluids at the surface.

For conventional oil, W/O emulsion with smaller droplet size is stable, which could be obtained by a large stirring rate. However, the stability of W/O emulsion will be weakened with large water cuts and high temperatures [8-10]. Actually, the active oil components at the water-oil interface are decisive for the stability of the heavy oil emulsion, and water release rates are decreased when large contents of asphaltene and resin are found in oil [11]. At the same time, the stability of emulsion under oscillation with small amplitude significantly relates to the complex modulus of asphaltene and resin [12]. In view of the stability of the water droplets in the emulsion, addition of asphaltene and resin could strengthen the stability of water-benzene emulsion [13-17]. Gray correlation entropy analysis of experimental results indicates that the stability of W/O emulsion relates to the SARA components of heavy oil and organic heteroatoms [18]. The stability of emulsion depends on the interfacial film strength, oil phase viscosity, droplet size, and interfacial tension [19, 20]; thus, the amount of interfacial active substances in crude oil is important for the formation of emulsions [21-26]. The active substances such as asphaltene and resin which accumulate at the oil-water interface increase the strength of the interface film and enhance the stability of the emulsion and the dissolution state of asphaltenes in crude oil, which determine the stability of the emulsion [27]. At the same time, paraffin and simulated water cannot form stable emulsions compared to oil with large contents of asphaltene and resin [28]. Compared to resin, asphaltene is found more active at the interfacial film between oil and water [29-31]. The results of the above literatures are obtained for heavy oil emulsions generated under low temperature (below $100^{\circ} \mathrm{C}$ ), and scarce research work on heavy oil emulsion under high temperature has been provided, such as in thermal recovering processes.

The mobility of heavy oil in thermal processes will be remarkably decreased because of in situ W/O emulsion generation, which could affect heavy oil recovery efficiency and increase the difficulty of artificial lift and surface separation. In order to investigate the effect of interfacial properties on the stability of heavy oil emulsion in thermal processes, various emulsions are generated to simulate heavy oil and water under different temperatures; stirring rates; contents of asphaltene, resin, and wax of the simulated heavy oil; and water salinities based on a real reservoir. Then, the viscosity of the W/O emulsion, IFV, IFT, and dehydration rate are primarily measured. In addition, the microscopic morphology of the emulsions generated is observed. Based on the measurement results, the effect of interfacial properties of water and heavy oil on emulsion stability is discussed in detail.

\section{Experiments}

2.1. Materials and Apparatus. The used heavy oils were sampled from 3 typical thermal stimulated wells in the Bohai Oilfield. The viscosities of the produced fluids and dehydrated
TABLE 1: Viscosity at $20^{\circ} \mathrm{C}$ of produced fluids and dehydrated crude oil from 3 typical thermal recovered wells in Bohai Oilfield ( $\mathrm{mPa} \cdot \mathrm{s})$.

\begin{tabular}{llll}
\hline Well & Well 1 & Well 2 & Well 3 \\
\hline Production fluid & 34976 & 26100 & 35147 \\
Dehydrated heavy oil & 14788 & 12005 & 15052 \\
\hline
\end{tabular}

crude oil are listed in Table 1. It shows that the viscosity of the emulsified heavy oils is about 2 times that of the dehydrated heavy oils, which would significantly impact the viscosity of heavy oil emulsion.

The difference between the viscosities of the heavy oil samples relates to the water cut and emulsion state. The microscopic images of the produced fluids (as shown in Figure 1) show the state of water in heavy oil emulsions, and the sizes of the water droplets are less than $1 \mu \mathrm{m}$ for the wells except the sample from Well 1 in which the size of large water droplets is up to $5 \mu \mathrm{m}$. All the three heavy oil samples show stable emulsion status without water released from samples of Well 1 and Well 2 at the initial reservoir temperature $\left(55^{\circ} \mathrm{C}\right)$ after 18 days, and only $4.2 \%$ water was released from the sample of Well 3.

The viscosity of the heavy oil used is $2652 \mathrm{mPa} \cdot \mathrm{s}$ at $50^{\circ} \mathrm{C}$, the density at $20^{\circ} \mathrm{C}$ is $0.96 \mathrm{~g} / \mathrm{cm}^{3}$, and SARA contents are $48.02 \mathrm{wt} \%, 27.46 \mathrm{wt} \%, 23.09 \mathrm{wt} \%$, and $1.43 \mathrm{wt} \%$, respectively.

The used water is similar to the formation water. The specific ion composition of the formation water is shown in Table 2; the total salinity is $1652 \mathrm{mg} / \mathrm{L}$. In the emulsion experiments with different salinities, the salinity is varied by adding $\mathrm{NaCl}$.

The aviation kerosene used is produced by Changshun Tongxing Petrochemical Products Co., Ltd., with an oilwater interfacial tension of $46 \mathrm{mN} / \mathrm{m}$ at room temperature.

The emulsions were prepared with heavy oil and simulated water by a high-speed emulsifier IKA-T18, IKA Company. The heavy oil emulsions under high temperature conditions in the thermal recovery process were observed with a visual PVT device, Sanchez Technologies, France. The viscosity of the emulsions was measured by a RS 6000 HAAKE rheometer, and IFV was measured with an MCR301 interfacial rheometer (Anton Paar). The microscopic morphology of the emulsion was observed by an SVT20N video rotating droplet tension meter (DataPhysics Company).

\subsection{Experimental Methods}

2.2.1. Measurements of Heavy Oil Emulsions at Different Temperatures and Stirring Rates. The mixtures of dehydrated heavy oil and simulated water are prepared by the volume ratio of $7: 3$ ( $35 \mathrm{~mL}$ heavy oil and $15 \mathrm{~mL}$ water). The mixture is added to the visual PVT device to generate heavy oil emulsions at the pressure of $5 \mathrm{MPa}$, at the given temperatures of $55^{\circ} \mathrm{C}, 100^{\circ} \mathrm{C}, 150^{\circ} \mathrm{C}$, and $180^{\circ} \mathrm{C}$ in consideration of the different locations of the heavy oil reservoir stimulated by thermal recovery processes. The stirring rates are $1400 \mathrm{r} / \mathrm{min}, 4200 \mathrm{r} / \mathrm{min}, 7000 \mathrm{r} / \mathrm{min}$, and $14000 \mathrm{r} / \mathrm{min}$. Then, the heavy oil emulsions obtained are sampled out 


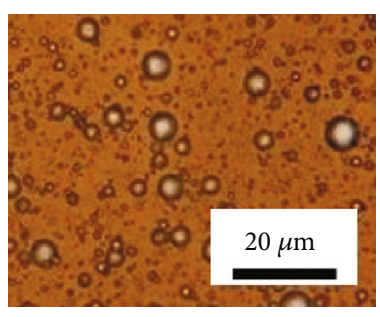

(a) Well 1

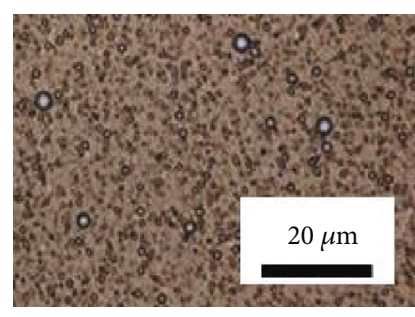

(b) Well 2

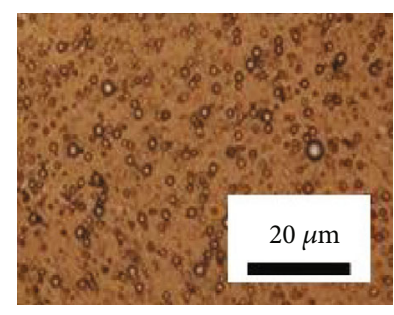

(c) Well 3

FIgURE 1: Microscopic images of the produced fluid of thermal recovery wells.

TABLE 2: The ion composition of simulated formation water.

\begin{tabular}{lcccccccc}
\hline Ion & $\mathrm{Cl}^{-}$ & $\mathrm{SO}_{4}{ }^{2-}$ & $\mathrm{HCO}_{3}{ }^{-}$ & $\mathrm{CO}_{3}{ }^{-}$ & $\mathrm{Mg}^{2+}$ & $\mathrm{Ca}^{2+}$ & $\mathrm{Na}^{+}$ & $\mathrm{K}^{+}$ \\
\hline Content $(\mathrm{mg} / \mathrm{L})$ & 63.6 & 8.06 & 700.72 & 34.9 & 2.29 & 8.12 & 827.38 & 7.14 \\
\hline
\end{tabular}

for the measurements of the viscosity, IFV, IFT, and microscopic morphology.

2.2.2. Preparation of the Simulated Oil with Different Contents of Asphaltene, Resin, and Wax. A certain amount of asphaltene separated from the heavy oils is weighed, and then the asphaltene is placed in a certain amount of xylene. The asphaltene and xylene are mixed by using an ultrasonic cleaner to completely dissolve the asphaltene, then a certain amount of aviation kerosene is added with a proper shake. The simulated oil is stored into a brown bottle. The simulated oil with different contents of resin or wax is prepared by a similar method of the oil with asphaltene.

In the separation experiments of the three components from crude oil, $\mathrm{n}$-pentane was added to $100 \mathrm{~g}$ of dehydrated crude oil with the volume ratio of crude oil to n-pentane of $1: 30$, while stirring the mixture with a glass rod for $20 \mathrm{~min}$. When the mixture was settled for 3 days at room temperature, the precipitated asphaltene component was filtered by a Brinell funnel with filter paper and washed with npentane for 3 times. The asphaltene component on the filter paper was dried in a vacuum oven at $50^{\circ} \mathrm{C}$ to obtain the asphaltene component.

The activated silica gel was added to the mixture of npentane and the remaining crude oil without asphaltene, and the mass ratio of silica gel to crude oil was 20 . Then, the mixture was stirred and adsorbed until it was colorless. Evaporate the mixture in a rotary evaporator, then dry it in a vacuum oven at $50^{\circ} \mathrm{C}$ until the mass is constant, and the wax was separated.

The adsorbed silica gel was washed with a mixture of benzene and ethanol with the ratio of $1: 1$, and the volume ratio of the mixture to crude oil was 25 . After stirring for up to 3 days, the mixture of benzene and ethanol is evaporated from the silica gel in a rotary evaporator, then the evaporated benzene and ethanol is added to the mixture; this step is repeated until the color of the silica gel becomes lighter, and then it is placed into a vacuum oven to dry at $50^{\circ} \mathrm{C}$ until the mass is constant and the resin is obtained.

2.2.3. Measurement of IFV and IFT of the Emulsions. IFV of the emulsion is measured by the interfacial rheometer, under the experimental temperature of $30^{\circ} \mathrm{C}$ during the measurement. $130 \mathrm{~mL}$ of water is added to the measuring cell to the measuring line, and the conical probe is carefully adjusted to be tangent to the water surface. Then, oil is slowly added to the syringe up to $10 \mathrm{~mm}$ above the taper side. The measurement is started up after the balance for a certain period of time.

IFT of the emulsion is measured by a SVT20N video rotary droplet tension meter. The experimental temperature is $80^{\circ} \mathrm{C}$ during the measurement.

2.2.4. Microscopic Observation and Droplet Size Analysis of Heavy Oil Emulsion. Microscopic observations of the emulsions generated are performed by an Olympus BX53 microscope, and the observed samples were prepared by cell scraping. This method has the advantages of a uniform smear, large photographic area, and simple operation as well as the thickness of the oil film being suitable for clear pictures. It is also possible to avoid the extrusion deformation of the droplets when the coverslip is tableted and prevent the influence of wettability of the coverslip on the droplet morphology.

\section{Results and Discussion}

3.1. Effect of Temperature and Stirring Rate on the Emulsion Stability. The intervention of external energy will affect the formation and stability of the heavy oil emulsion. In thermal processes, the emulsification of heavy oil and water will be driven by heating and driving in the reservoir. The emulsion generated under different temperatures and stirring rates simulating thermal recovery processes is measured in terms of viscosity, water release volume, and microscopic morphology. 


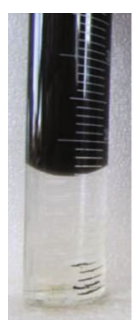

\#1

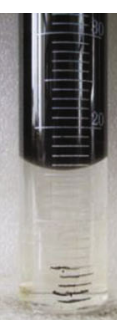

\#2

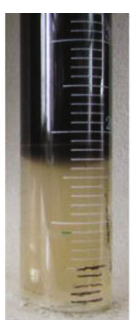

$\# 3$

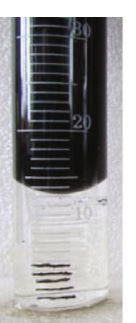

\#4

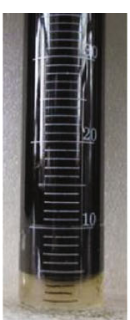

\#5

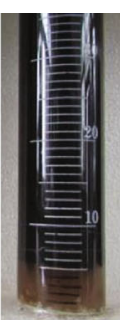

\#6

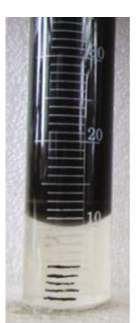

\#7

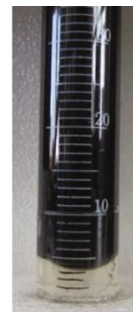

$\# 8$

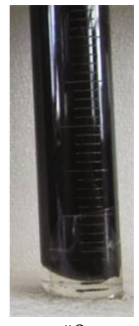

\#9

FIGURE 2: Images of water release from the emulsions at different temperatures and stirring rates.

The heavy oil emulsions obtained at different temperatures of $55^{\circ} \mathrm{C}, 100^{\circ} \mathrm{C}, 150^{\circ} \mathrm{C}$, and $180^{\circ} \mathrm{C}$ were placed in an oven and kept at a constant temperature of $50^{\circ} \mathrm{C}$ for $48 \mathrm{~h}$. Then, the viscosity of the emulsions was measured. The images of the emulsions observed are shown in Figure 2. The results of viscosity measurement are listed in Table 3. It shows that the viscosity of heavy oil emulsions is significantly increased under increasing temperature and stirring rate. As for the emulsions obtained at the same stirring rate of $4200 \mathrm{r} / \mathrm{min}$, the emulsion viscosity is increased from $2251.04 \mathrm{mPa} \cdot \mathrm{s}$ emulsified at $55^{\circ} \mathrm{C}$ to $3478.24 \mathrm{mPa} \cdot \mathrm{s}$ emulsified at $180^{\circ} \mathrm{C}$, up to $54.5 \%$ increase obtained. At the same time, the viscosity of the emulsion obtained at $150^{\circ} \mathrm{C}$ is increased from $2810.41 \mathrm{mPa} \cdot \mathrm{s}$ emulsified at $1400 \mathrm{r} / \mathrm{min}$ to $4267.10 \mathrm{mPa} \cdot \mathrm{s}$ emulsified at $7000 \mathrm{r} / \mathrm{min}$; up to $51.8 \%$ increase was obtained. It indicates that the higher viscosity of emulsion could be obtained after heating treatment such as a thermal recovery process, and stirring treatment such as flow rate in the porous media or tubing.

The water release volume from the heavy oil emulsion generated at $150^{\circ} \mathrm{C}$ and different stirring rates are listed in Table 4 . The water release volume is evidently decreased for the emulsion obtained with a higher stirring rate. After settling for $72 \mathrm{~h}$, the water release volume of the emulsion obtained at $7000 \mathrm{r} / \mathrm{min}$ is only $2.0 \mathrm{~mL}$, less than that of the emulsion obtained at $4200 \mathrm{r} / \mathrm{min}(3.0 \mathrm{~mL})$, and much less than that of the emulsion obtained at $1400 \mathrm{r} / \mathrm{min}$ (up to $15.0 \mathrm{~mL}$ ).

Actually, the released water volume or stability of emulsion is related to the emulsification state. The microscope images of heavy oil emulsions at different temperatures and different stirring rates are shown in Figure 3. It shows that the size of water droplets is enlarged while the temperature and stirring rate increase, and the size of the largest droplets is almost $10 \mu \mathrm{m}$. At the same temperature, the heavy oil is easy to emulsify with simulated water as the stirring rate increases, and the stability of the heavy oil emulsion is enhanced as well.

At the same time, the microscopic images of the emulsions indicate that the water and heavy oil interfaces of the emulsions vary with temperature and stirring rate. For the emulsion obtained at lower temperatures, the interface between water droplets and heavy oil looks distinct, dark, and thin (see Figure 4(a)). It indicates that some heavy components are accumulated at the interface, which contribute to the increased IFV and the decreased IFT of the emulsion, according to the stability of the emulsion. However, for the emulsions obtained at higher temperatures (over $100^{\circ} \mathrm{C}$ )
TABle 3: The viscosity of heavy oil emulsions at $50^{\circ} \mathrm{C}$ at different temperatures and stirring rates.

\begin{tabular}{lccc}
\hline Number & $\begin{array}{c}\text { Simulation conditions } \\
\text { Temperature } \\
\left({ }^{\circ} \mathrm{C}\right)\end{array}$ & $\begin{array}{c}\text { Stirring rate } \\
(\mathrm{r} / \mathrm{min})\end{array}$ & $\begin{array}{c}\text { Viscosity at } 50^{\circ} \mathrm{C} \\
(\mathrm{mPa} \cdot \mathrm{s})\end{array}$ \\
\hline 1 & & 1400 & 2201.06 \\
2 & 55 & 4200 & 2251.04 \\
3 & & 7000 & 2366.41 \\
\hline 4 & & 1400 & 2651.42 \\
5 & 100 & 4200 & 3402.84 \\
6 & & 7000 & 3529.73 \\
\hline 7 & & 1400 & 2810.41 \\
8 & 150 & 4200 & 3478.24 \\
9 & & 7000 & 4267.10 \\
\hline 10 & 180 & 4200 & 3652.78 \\
\hline
\end{tabular}

TABLE 4: The water release volume from the heavy oil emulsions obtained at $150^{\circ} \mathrm{C}$ and different stirring rates $(\mathrm{mL})$.

\begin{tabular}{lccc}
\hline \multirow{2}{*}{ Settling time $(\mathrm{h})$} & \multicolumn{3}{c}{ Stirring rate $(\mathrm{r} / \mathrm{min})$} \\
\hline 0 & 1400 & 4200 & 7000 \\
24 & 6.8 & 2.0 & 1.0 \\
48 & 10.0 & 3.0 & 2.0 \\
72 & 12.5 & 3.0 & 2.0 \\
\hline
\end{tabular}

and stirring rates, the water and oil interfaces look very nebulous, indistinct, and thick (see Figure 4(b)).

There are larger central droplets and small surrounding droplets generated in the emulsion, and the active components of heavy oil accumulated at the indistinct thick interface are not as heavy as those of the emulsion obtained at the low temperatures. Such indistinct interfaces may be miscible between heavy oil and water, and the IFV and IFT should be different from the thin interfaces of the emulsion obtained at low temperature and stirring rate. In summary, the large stability of emulsions obtained at high temperature and high stirring rate ought to be related to the indistinct thick interface which makes the droplets connect tightly and the system more miscible. 


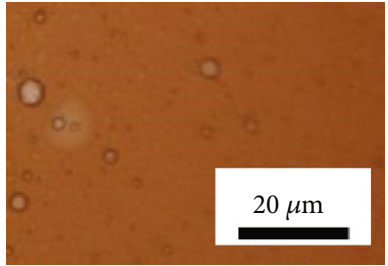

(a) $1400 \mathrm{r} / \mathrm{min}, 55^{\circ} \mathrm{C}$

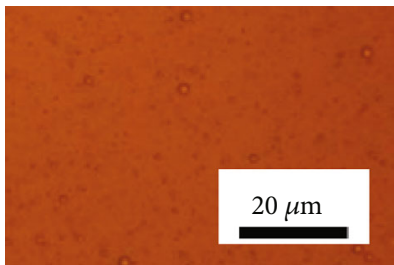

(d) $1400 \mathrm{r} / \mathrm{min}, 100^{\circ} \mathrm{C}$

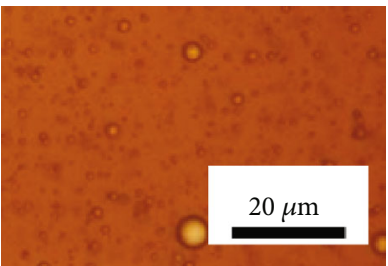

(g) $1400 \mathrm{r} / \mathrm{min}, 150^{\circ} \mathrm{C}$

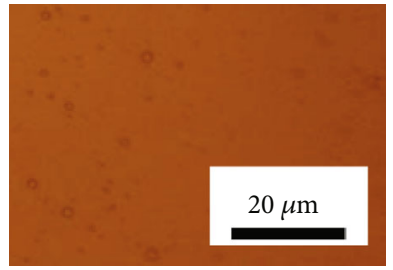

(b) $4200 \mathrm{r} / \mathrm{min}, 55^{\circ} \mathrm{C}$

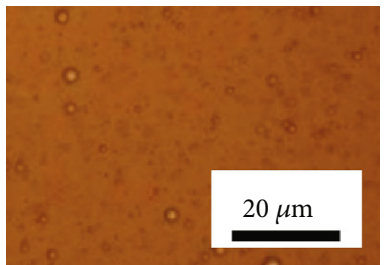

(e) $4200 \mathrm{r} / \mathrm{min}, 100^{\circ} \mathrm{C}$

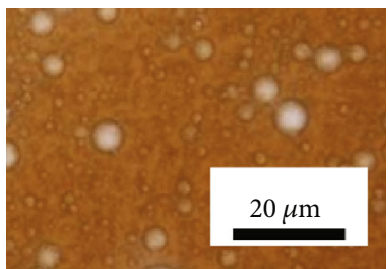

(h) $4200 \mathrm{r} / \mathrm{min}, 150^{\circ} \mathrm{C}$

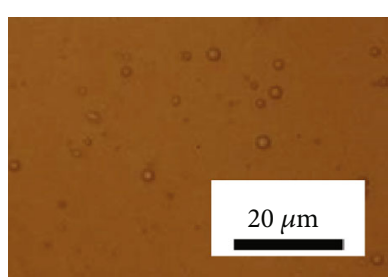

(c) $7000 \mathrm{r} / \mathrm{min}, 55^{\circ} \mathrm{C}$

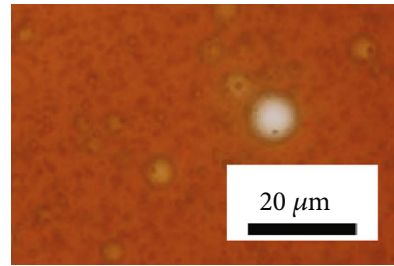

(f) $7000 \mathrm{r} / \mathrm{min}, 100^{\circ} \mathrm{C}$

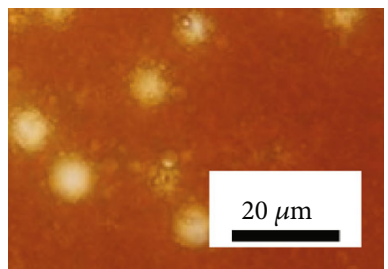

(i) $7000 \mathrm{r} / \mathrm{min}, 150^{\circ} \mathrm{C}$

FIGURE 3: Microscope images of heavy oil emulsions at different temperatures and different stirring rates.

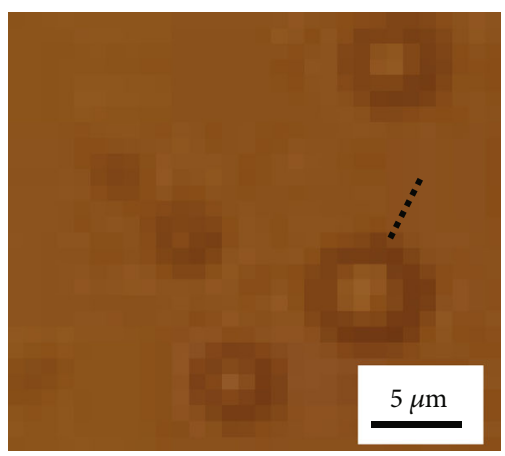

(a) $7000 \mathrm{r} / \mathrm{min}, 55^{\circ} \mathrm{C}$

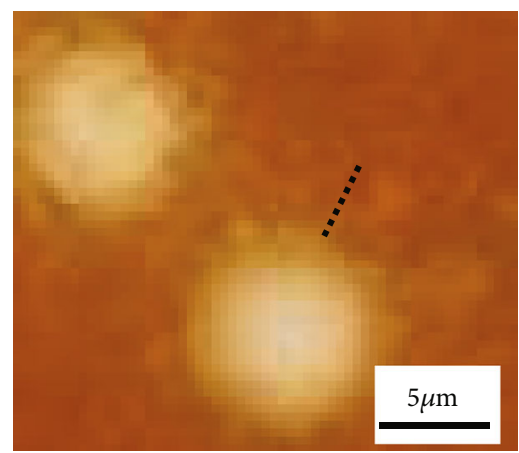

(b) $7000 \mathrm{r} / \mathrm{min}, 150^{\circ} \mathrm{C}$

FIGURE 4: Microscope images of water droplets with different interface characteristics.

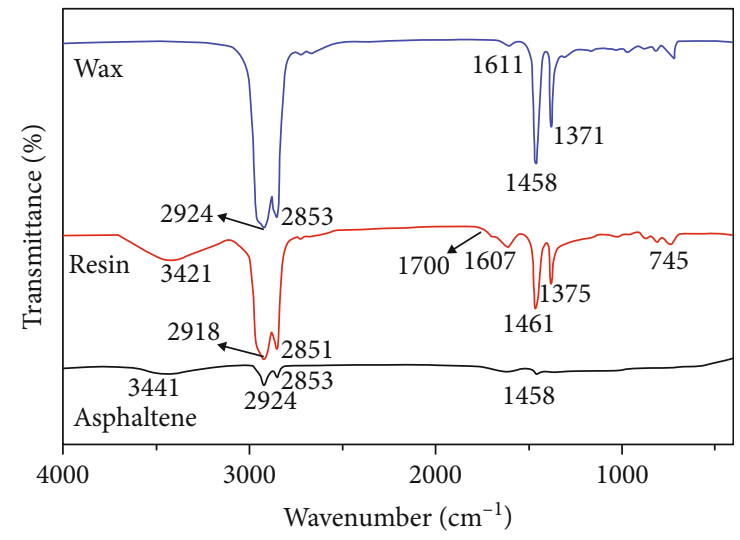

FIGURE 5: The infrared spectrum of the asphaltene, resin, and wax obtained.
TABle 5: The IFT at $80^{\circ} \mathrm{C}$ of the emulsions with different contents of asphaltene, resin, or wax.

\begin{tabular}{lcccccc}
\hline \multirow{2}{*}{ Asphaltene } & Content (wt\%) & 0 & 0.5 & 1.0 & 2.0 & / \\
& IFT $(\mathrm{mN} / \mathrm{m})$ & 14.67 & 8.74 & 7.99 & 7.58 & $/$ \\
\hline \multirow{2}{*}{ Resin } & Content $(\mathrm{wt} \%)$ & 0 & 1.0 & 3.0 & 7.0 & 10.0 \\
& IFT $(\mathrm{mN} / \mathrm{m})$ & 14.67 & 9.82 & 8.80 & 7.42 & 7.00 \\
\hline \multirow{2}{*}{ Wax } & Content $(\mathrm{wt} \%)$ & 0 & 1.0 & 3.0 & 7.0 & 10.0 \\
& IFT $(\mathrm{mN} / \mathrm{m})$ & 14.67 & 14.54 & 14.77 & 15.03 & 15.01 \\
\hline
\end{tabular}

3.2. Effect of Heavy Oil Composition on Oil-Water Interface Properties and Emulsion Stability. The characteristics such as stability and droplet size of the emulsion are related 


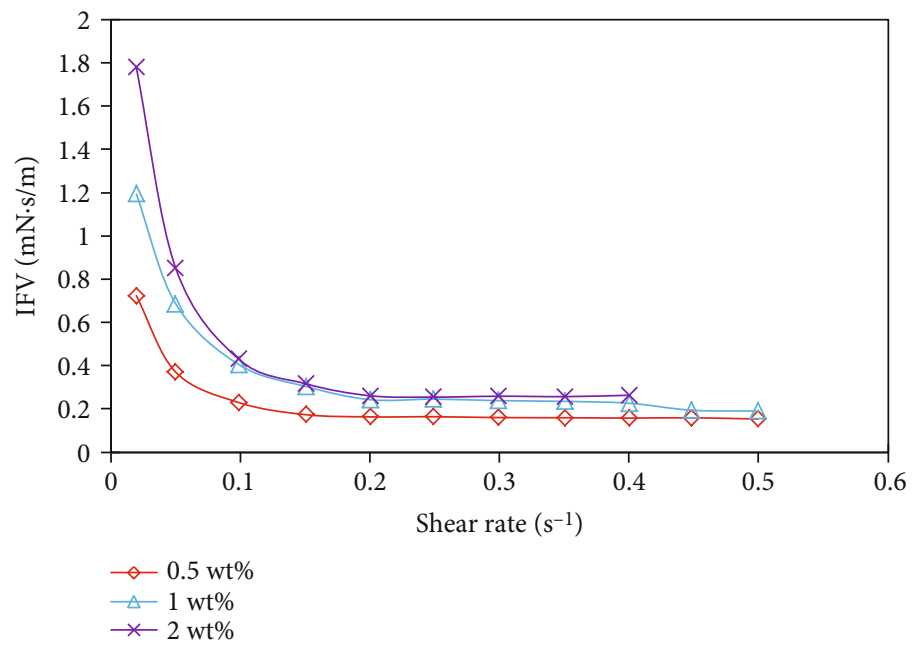

FIgURE 6: Influence of the asphaltene content on IFV.

to the active material accumulated at the interface besides temperature and stirring rate. In order to study the effect of heavy components such as asphaltene, resin, and wax on the emulsion stability, the emulsion of heavy oil with different contents of asphaltene, resin, or wax is made up and measured in terms of IFV, IFT, and water release volume. The asphaltene, resin, and wax are separated from the heavy oil, and their correct groups are analyzed by the infrared spectrum. For the simulation oil with different contents of asphaltene, the asphaltene is first dissolved in xylene and then mixed with aviation kerosene to make the simulated oil with different asphaltene contents. The simulation oil with different resin contents is prepared by dissolving certain contents of resin in aviation kerosene, and the simulation oil with different wax contents is prepared by dissolving certain contents of wax in aviation kerosene.

The infrared spectra of the asphaltene, resin, and wax separated from heavy oil are shown in Figure 5. The infrared spectrum of asphaltene shows that $2924 \mathrm{~cm}^{-1}$ and $2853 \mathrm{~cm}^{-1}$ are the stretching vibration absorption peaks of saturated $\mathrm{C}-\mathrm{H}$ and $1458 \mathrm{~cm}^{-1}$ and $1376 \mathrm{~cm}^{-1}$ are the bending vibration absorption peaks of methyl and methylene groups containing hydrocarbons. $3441 \mathrm{~cm}^{-1}$ may be the associated $\mathrm{O}-\mathrm{H}$ stretching vibration absorption peak, and $1611 \mathrm{~cm}^{-1}$ is the characteristic absorption peak of $\mathrm{C}=\mathrm{O}$. Therefore, it can be seen that there are aromatic hydrocarbons and saturated alkanes and compounds containing carboxyl groups and carbonyl groups in asphaltene. These structures are mainly interfaceactive components.

The infrared spectrum of the resin shows that $2918 \mathrm{~cm}^{-1}$ and $2851 \mathrm{~cm}^{-1}$ are the stretching vibration absorption peaks of saturated $\mathrm{C}-\mathrm{H}$, and $1461 \mathrm{~cm}^{-1}$ and $1375 \mathrm{~cm}^{-1}$ are the bending vibration absorption peaks of methyl and methylene groups. The substance contains hydrocarbons. $3421 \mathrm{~cm}^{-1}$ has a broad absorption peak, which may be the stretching vibration of $\mathrm{O}$ $\mathrm{H}$ and $\mathrm{N}-\mathrm{H} .1700 \mathrm{~cm}^{-1}$ is the characteristic absorption peak of $\mathrm{C}=\mathrm{O}$, and $1607 \mathrm{~cm}^{-1}$ is the characteristic absorption peak of aromatic hydrocarbon skeleton $\mathrm{C}=\mathrm{C}$. It indicates that the gum may contain acid, ester, alcohol, phenol, and other groups; these groups are the main interface-active components.

The infrared spectrum of the wax obtained shows that $2924 \mathrm{~cm}^{-1}$ and $2853 \mathrm{~cm}^{-1}$ are the stretching vibration absorption peaks of saturated C-H, and $1458 \mathrm{~cm}^{-1}$ and $1371 \mathrm{~cm}^{-1}$ are the bending vibration absorption peaks of methyl and methylene groups, and it can be seen that the main component of the wax is hydrocarbons. There is no obvious absorption peak at $1600 \mathrm{~cm}^{-1}$, no absorption peak at $>3000 \mathrm{~cm}^{-1}$, and no stretching vibration absorption peak of unsaturated $\mathrm{C}-\mathrm{H}$ or aldehyde hydrogen, so the wax component does not contain $\mathrm{C}=\mathrm{O}$ and $\mathrm{O}-\mathrm{H} / \mathrm{N}-\mathrm{H}$ structures, and these structures are mainly interface-active components.

The IFT of the emulsions at $80^{\circ} \mathrm{C}$ generated with heavy oil with different contents of asphaltene, resin, or wax are listed in Table 5. The contents of asphaltene are $0 \mathrm{wt} \%$ $2 \mathrm{wt} \%$, the contents of resin are $0 \mathrm{wt} \%-10 \mathrm{wt} \%$, and the contents of wax are $0 \mathrm{wt} \%-10 \mathrm{wt} \%$ as well.

It shows that the IFT of the emulsion obtained with the simulation oil is significantly decreased as asphaltene content or resin content is increasing. As the asphaltene content increases from $0 \mathrm{wt} \%$ to $2 \mathrm{wt} \%$, the interfacial tension decreases from $14.67 \mathrm{mN} / \mathrm{m}$ to $7.58 \mathrm{mN} / \mathrm{m}$, about $48.3 \%$ decrease in IFT obtained. As the resin content increases from $0 \mathrm{wt} \%$ to $10 \mathrm{wt} \%$, the interfacial tension decreases from $14.67 \mathrm{mN} / \mathrm{m}$ to $7.00 \mathrm{mN} / \mathrm{m}$, about $52.3 \%$ decrease in IFT obtained. At the same content, the effect of asphaltene on IFT is more evident than that of resin; it indicates that asphaltene is more active at the interfacial film between oil and water than resin. However, IFT of simulation oil and water remains almost unchanged or even enlarged with different contents of wax; it indicates that there is no active substance in wax, which mainly consists of saturated and aromatic hydrocarbons.

The influence of the oil content of asphaltene, resin, and wax on the IFV of the emulsion is shown in Figures 6, 7, and 8 , respectively.

Figure 6 shows that the IFV at a shearing rate of $0.25 \mathrm{~s}^{-1}$ increases gradually from $0.16 \mathrm{mN} \cdot \mathrm{s} / \mathrm{m}$ to $0.26 \mathrm{mN} \cdot \mathrm{s} / \mathrm{m}$ as the 


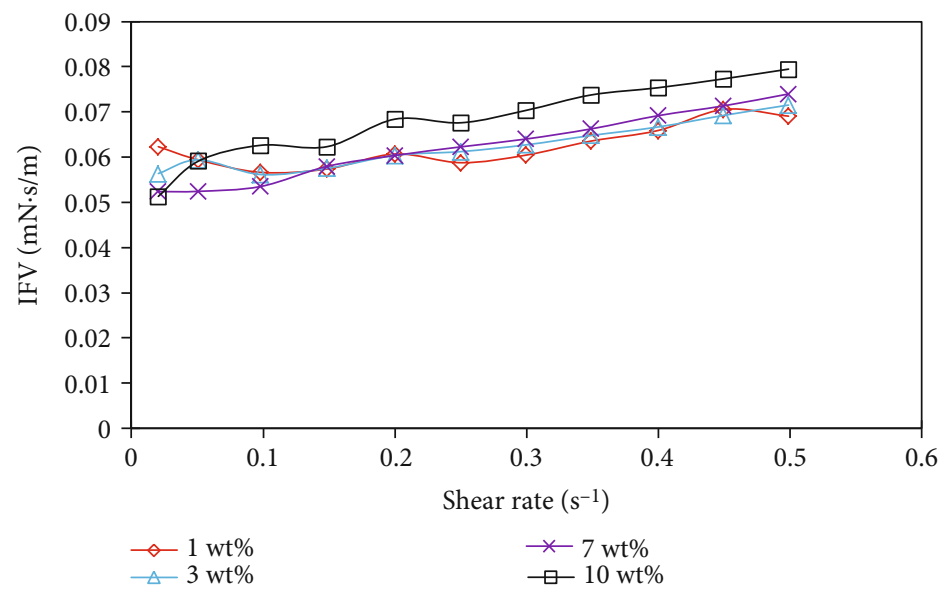

FIGURE 7: Influence of the resin content on IFV.

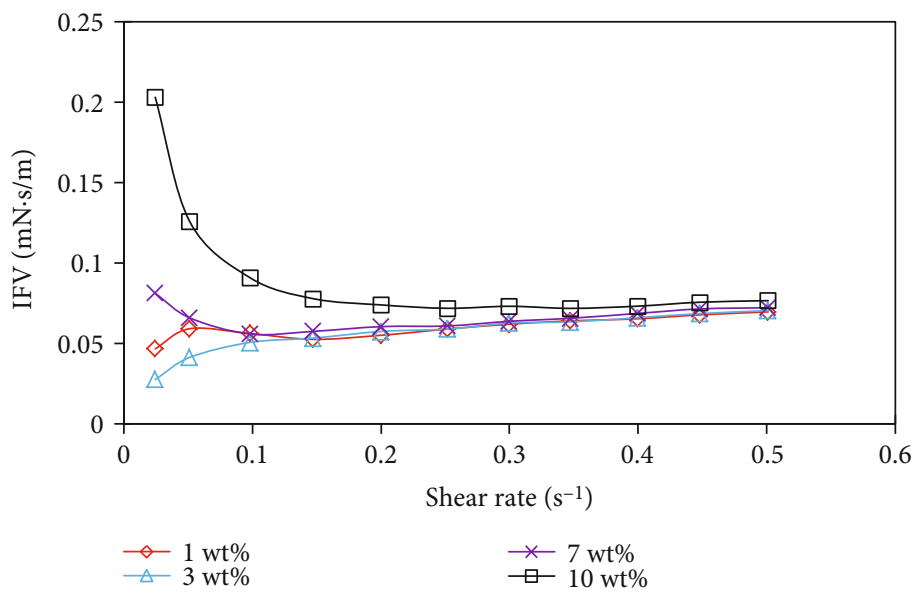

Figure 8: Influence of the wax content on IFV.

asphaltene content increases from $0.5 \mathrm{wt} \%$ to $2.0 \mathrm{wt} \%$, and the IFV is decreased as the shearing rate is increasing. When the shearing rate increases from $0.02 \mathrm{~s}^{-1}$ to $0.2 \mathrm{~s}^{-1}$, the IFV is decreased rapidly from $1.78 \mathrm{mN} \cdot \mathrm{s} / \mathrm{m}$ to $0.26 \mathrm{mN} \cdot \mathrm{s} / \mathrm{m}$. When the shearing rate increases further from $0.2 \mathrm{~s}^{-1}$ to $0.5 \mathrm{~s}^{-1}$, the IFV fluctuates between $0.25 \mathrm{mN} \cdot \mathrm{s} / \mathrm{m}$ and $0.26 \mathrm{mN} \cdot \mathrm{s} / \mathrm{m}$ and finally tends to keep constant.

Figure 7 shows that the IFV at a shearing rate of $0.25 \mathrm{~s}^{-1}$ increases gradually from $0.057 \mathrm{mN} \cdot \mathrm{s} / \mathrm{m}$ to $0.067 \mathrm{mN} \cdot \mathrm{s} / \mathrm{m}$ as the resin content increases from $1.0 \mathrm{wt} \%$ to $10.0 \mathrm{wt} \%$. At the same time, the IFV of the emulsion obtained with different contents of resin is increased as the shearing rate is increasing. When the content of resin is high, more interfacial active substances are present. The interface formed at the oil-water interface has a high strength, so the IFV is relatively large, which is basically from $0.05 \mathrm{mN} \cdot \mathrm{s} / \mathrm{m}$ to $0.08 \mathrm{mN} \cdot \mathrm{s} / \mathrm{m}$. It indicates that there are more interface-active substances in asphaltene and resin.

Figure 8 shows that the IFV of the wax simulated oil and the simulated water changes in a small range of $0.04 \mathrm{mN} \cdot \mathrm{s} / \mathrm{m}$ $0.08 \mathrm{mN} \cdot \mathrm{s} / \mathrm{m}$ as the wax content increases from $0 \mathrm{wt} \%$ to $7.0 \mathrm{wt} \%$. And the IFV for the simulated oil with a wax content of $10.0 \mathrm{wt} \%$ first clearly decreases and eventually stabilizes at
TABLE 6: The water volume released from the emulsions obtained with different contents of asphaltene, resin, and wax.

\begin{tabular}{lcccc}
\hline \multirow{2}{*}{ Asphaltene } & Content $(\mathrm{wt} \%)$ & 0 & 0.1 & 1.0 \\
& Water volume $(\mathrm{mL})$ & 7.5 & 5.0 & 0 \\
\hline \multirow{2}{*}{ Resin } & Content $(\mathrm{wt} \%)$ & 0 & 0.1 & 1.0 \\
& Water volume $(\mathrm{mL})$ & 7.5 & 4.0 & 5.5 \\
\hline \multirow{2}{*}{ Wax } & Content $(\mathrm{wt} \%)$ & 0 & 0.1 & 1.0 \\
& Water volume $(\mathrm{mL})$ & 7.5 & 6.5 & 6 \\
\hline
\end{tabular}

$0.076 \mathrm{mN} \cdot \mathrm{s} / \mathrm{m}$ with a rising shearing rate. It is mainly due to limited active interface substances in the wax so that the strength of the interface formed at the oil-water interface is low, and no stable emulsion could be generated.

Therefore, IFV of emulsion with more asphaltene or resin accumulated at the interface is much larger than that with wax accumulated, and asphaltene and resin containing more interface-active substances can form a stronger interface.

The water release volumes of the emulsions generated with oil with different contents of asphaltene, resin, and wax are listed in Table 6. The contents of asphaltene, resin, 
TABLE 7: The IFT and viscosity of emulsion obtained with different salinities.

\begin{tabular}{|c|c|c|c|c|c|c|}
\hline Water salinity $(\mathrm{mg} / \mathrm{L})$ & 0 & 500 & 1000 & 3000 & 5000 & 10000 \\
\hline Interfacial tension at $80^{\circ} \mathrm{C}(\mathrm{mN} / \mathrm{m})$ & 6.58 & 7.28 & 8.71 & 8.55 & 7.70 & 6.49 \\
\hline Viscosity at $50^{\circ} \mathrm{C}(\mathrm{mPa} \cdot \mathrm{s})$ & 1122.53 & 3797.40 & 5624.20 & 4587.20 & 4983.90 & l \\
\hline
\end{tabular}

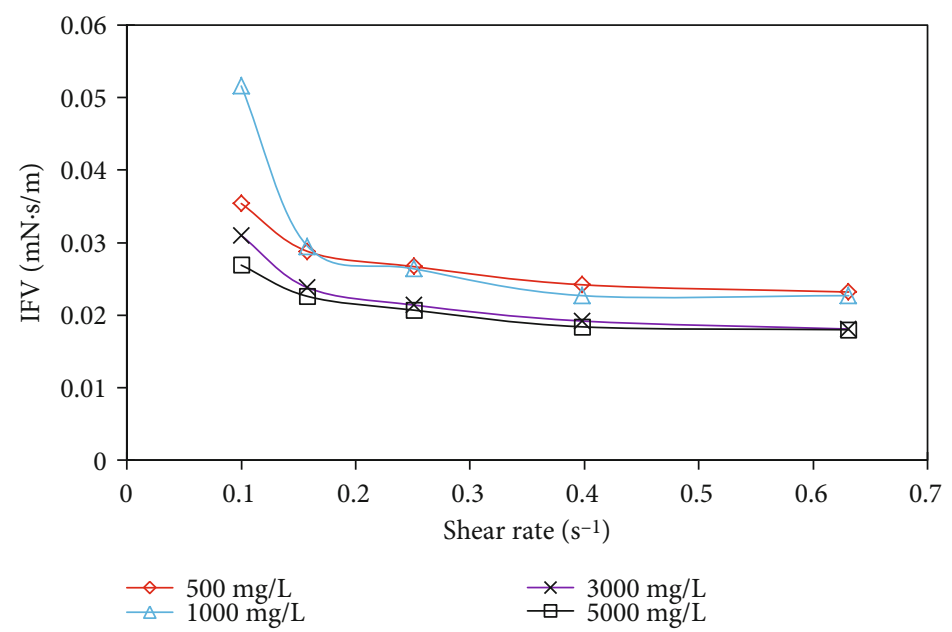

Figure 9: Influence of the water salinity on the interfacial shear viscosity between water and oil.

and wax to form simulated oils are $0.1 \mathrm{wt} \%$ and $1.0 \mathrm{wt} \%$. The released water volumes of the emulsions generated with the simulation oil and the simulation water are measured after settling for $1 \mathrm{~h}$ at $52^{\circ} \mathrm{C}$.

It can be seen from Table 6 that the water volumes released from the heavy oil emulsions gradually decrease as the asphaltene content increases, and there is no water released when the asphaltene content is increased to $1.0 \mathrm{wt} \%$. It indicates that emulsion stability is enhanced when the content of asphaltene in heavy oil is increased. For the simulation oil with $0.1 \mathrm{wt} \%$ and $1.0 \mathrm{wt} \%$ of resin, $4.0 \mathrm{~mL}$ and $5.5 \mathrm{~mL}$ of water are precipitated from the emulsion (the total water is $7.5 \mathrm{~mL}$ in the emulsion); it indicated that the emulsion with addition of resin is less stable than the emulsion with the addition of asphaltene. For the simulation oil with $0.1 \mathrm{wt} \%$ and $1.0 \mathrm{wt} \%$ of wax, $6.5 \mathrm{~mL}$ and $6 \mathrm{~mL}$ of water are released from the emulsion in $10 \mathrm{~min}$, and it indicates that wax has no evident influence on the emulsion.

\subsection{Effect of Water Salinity on the Interfacial Properties and} Emulsion Stability. The effects of water salinity on the interfacial properties and emulsion stability are investigated using the simulated water prepared with different salinities with addition of $\mathrm{NaCl}$, and the volume ratio of oil to water is $7: 3$ in the experiments. The viscosity at $50^{\circ} \mathrm{C}$ and the IFT at $80^{\circ} \mathrm{C}$ of the emulsions obtained with different salinities are listed in Table 7 . It shows that IFT of emulsion increases from $6.50 \mathrm{mN} / \mathrm{m}$ to $8.71 \mathrm{mN} / \mathrm{m}$ when the salinity of simulation water increases from $0 \mathrm{mg} / \mathrm{L}$ to $1000 \mathrm{mg} / \mathrm{L}$, then the IFT decreases to $6.49 \mathrm{mN} / \mathrm{m}$ at the salinity of $10000 \mathrm{mg} / \mathrm{L}$.

At the same time, the viscosity of the heavy oil emulsion formed is significantly greater than that of dehydrated heavy oil. When the salinity of the simulation water increases to $1000 \mathrm{mg} / \mathrm{L}$, the viscosity of the heavy oil emulsion is up to $5624.20 \mathrm{mPa} \cdot \mathrm{s}$, which is almost 5 times the dehydrated heavy oil.

The relationships between IFV of the emulsion of aviation kerosene and the simulation water with different salinities and shearing rates are shown in Figure 9. It shows that IFV is generally decreased as the salinity of the simulation water increases. In other words, increasing salinity of the simulation water could reduce the stability of the interfacial film and, accordingly, the emulsion. IFV of the emulsion with different salinities is gradually decreased with increasing shearing rate. This trend may be attributed to the fact that the formed interface film is unstable, and its structure is susceptible to shear failure.

The microscopic morphologies of the emulsions with heavy oil and simulation water with different salinities $(500 \mathrm{mg} / \mathrm{L}$ to $5000 \mathrm{mg} / \mathrm{L}$ ) at $14000 \mathrm{r} / \mathrm{min}$ for $10 \mathrm{~min}$ are observed at 1000 times with a microscope, and the microscope images obtained are shown in Figure 10. As the salinity increases, the density of the dispersed water in the heavy oil emulsion is increased too. The sizes of the water droplets in heavy oil emulsions formed with the salinity of $3000 \mathrm{mg} / \mathrm{L}$ and $5000 \mathrm{mg} / \mathrm{L}$ are up to $30 \mu \mathrm{m}$. The droplet size distribution of the emulsion obtained with a water salinity of $1000 \mathrm{mg} / \mathrm{L}$ uniformly ranges from $7 \mu \mathrm{m}$ to $15 \mu \mathrm{m}$. With increasing salinity, a diffusion layer formed by the active component of the 


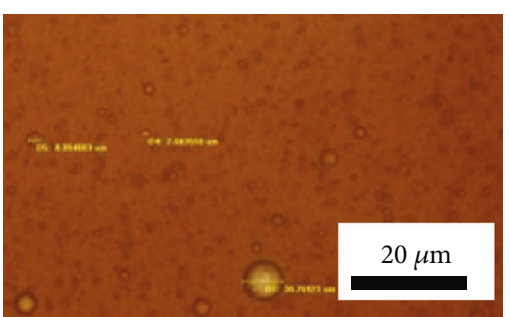

(a) $500 \mathrm{mg} / \mathrm{L}$

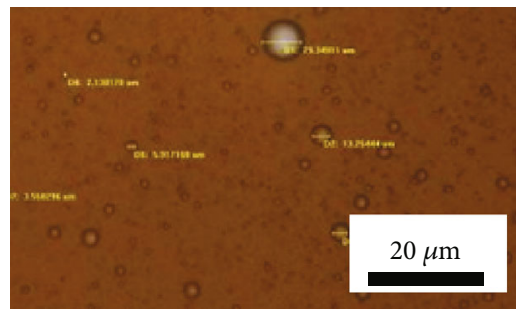

(c) $3000 \mathrm{mg} / \mathrm{L}$

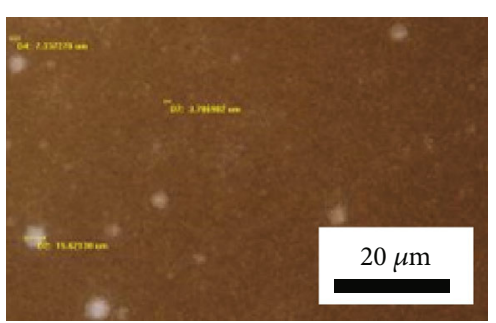

(b) $1000 \mathrm{mg} / \mathrm{L}$

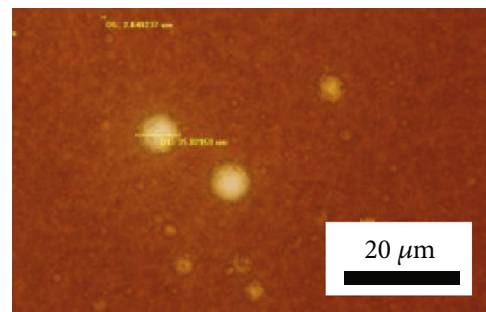

(d) $5000 \mathrm{mg} / \mathrm{L}$

FIGURE 10: Microscope images of the emulsions obtained with different water salinities.
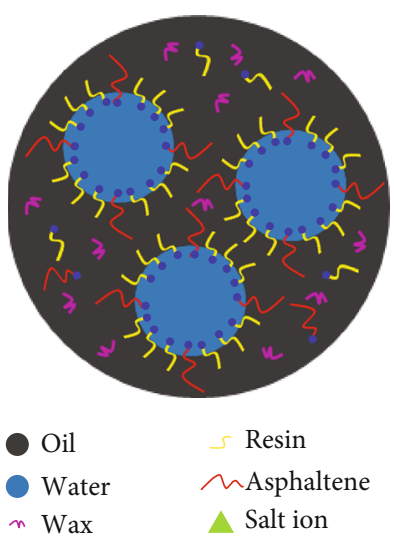

(a)
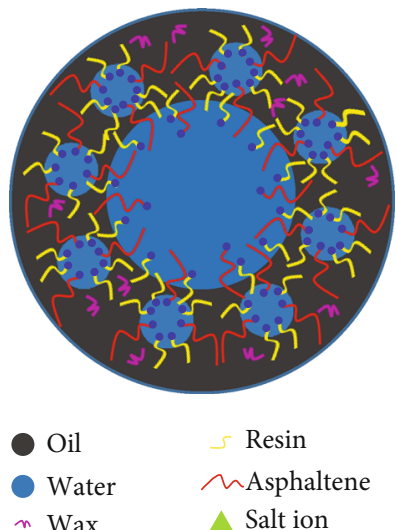

n Wax

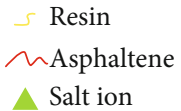

(b)
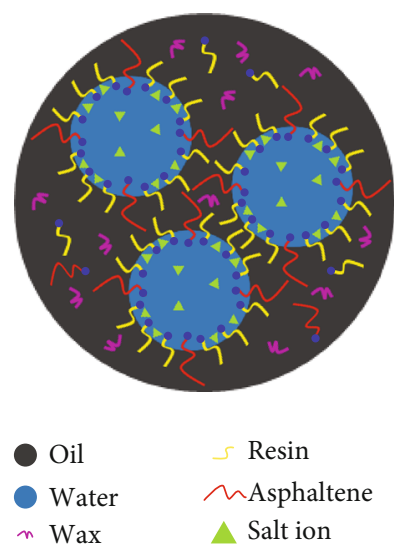

(c)

FIGURE 11: Schematic diagram of the mechanism of heavy oil-water emulsification.

cation will compress the interface. Therefore, the strength of the oil-water interface film will be decreased, and the stability of the emulsion will be reduced because the oil-water coalescence capability will be enhanced.

\subsection{Stabilization Mechanism of Heavy Oil Emulsion in} Thermal Recovery Process. While there are tremendous phase interfaces existing in the heavy oil emulsion, the total surface energy of the system is large and the system is a thermodynamically unstable system. The IFT of the water and heavy oil interface will promote the aggregation of the water droplets, and the system will become more stable when the IFT is decreased and the IFV is increased.

Asphaltene and resin contain much more polar active groups, aromatic hydrocarbon structures, and unsaturated hydrocarbon structures than the wax component, and the interfacial active substances may contain acids, esters, amines, and other substances with structures such as $\mathrm{O}-\mathrm{H}$,
$\mathrm{N}-\mathrm{H}$, and $\mathrm{C}=\mathrm{O}$. The interfacial active substances are inclined to be accumulated at the interface, and an ordered and strong interface will be formed to make the $\mathrm{W} / \mathrm{O}$ emulsion more stable.

The stability of the heavy oil emulsion generated under high temperature conditions of thermal recovery process is related to interface properties such as active components of asphaltene, resin, and salt ion and the state of the emulsified interface; the diagram of the mechanism of heavy oil emulsification under different conditions is shown in Figure 11.

Figure 11(a) shows the mechanism of emulsion generated under low temperature and stirring rate; active components such as asphaltene and resin in heavy oil accumulate at the water-oil interface and form a distinct, clear, thin interface, which makes the emulsion stable.

Figure 11(b) shows the mechanism of emulsion generated under a higher temperature and stirring rate, an indistinct thick interface is formed between the water and oil; 
usually, a central large water droplet will be accompanied by many small droplets, and the molecules of asphaltene and resin may connect the large droplet and the small droplet tightly. Such connection ought to make the interface miscible, thick, and indistinct, and asphaltene molecules with a long carbon chain and more aromatic rings have a stronger connection than resin. Accordingly, IFV of the emulsion is much larger than that of emulsion generated under low temperature and stirring rate, and a larger stability of the emulsion will be obtained as well. Therefore, the large stability of the emulsion generated under high temperature and stirring rate should be related to the indistinct thick interface and tight connection between droplets.

Figure 11(c) shows the mechanism of the heavy oil emulsion generated with water with certain salinities; the salt ion in water will accumulate at the interface, mainly react with polar groups of asphaltene and resin, and affect the stability in terms of IFV and IFT accordingly. The intermolecular interaction of substances at the interface such as asphaltene and resin will be decreased when more salt ions are accumulated at the interface. It could be concluded that the stability of water in heavy oil emulsion is mainly related to the large interfacial viscosity of the interface with much more heavy components such as asphaltene and resin accumulated compared to thin oil.

\section{Conclusions}

(1) The heavy oil emulsion produced from thermal recovered wells is much more stable, with little water released from the emulsion samples even after 18 days. At the same time, the viscosity of the heavy oil emulsions are about 2 times that of the dehydrated heavy oils

(2) The viscosity of heavy oil emulsions is significantly increased under increasing temperature and stirring rate just like the thermal recovery processes. At the same time, the size of water droplets in the emulsion will be enlarged when the temperature and stirring rate increase

(3) The interfaces between water and heavy oil in the emulsions generated at a higher temperature and a faster stirring rate are more indistinct and thicker than the interfaces obtained at a lower temperature. The active molecules of asphaltene and resin are accumulated at the interface and connect the central large droplet and the surrounding small droplets tightly. The size of the central droplet and the indistinct interface will be enlarged with increasing temperature and increasing stirring rate

(4) It should be noted that, compared to resin, the larger asphaltene molecules have a stronger connection because of their strong intermolecular force, larger IFV, and less IFT in the emulsions generated with heavy oil with higher contents of asphaltene and/or resin
(5) The interfacial viscosity of the oil-water interface is gradually decreased as the water salinity increases. The viscosity of the heavy oil emulsion is increased at first and then decreased over a certain salinity. The effect of salinity on emulsion stability maybe related to the reaction of the salt ion with interfacial active substances in asphaltene and resin

(6) The stability of water in heavy oil emulsion is mainly related to the large interfacial viscosity of the interface with the accumulation of much more heavy components such as asphaltene and resin compared to thin oil

\section{Data Availability}

Data will be available on request.

\section{Conflicts of Interest}

The authors declare that there is no conflict of interest regarding the publication of this paper.

\section{Acknowledgments}

This work was financially supported by the National Natural Science Foundation of China (No. 51774306) and National Key Scientific and Technological Project for the Oil \& Gas Field and Coalbed Methane of China (2016ZX05058-003009 and 2016ZX05031002-004-002).

\section{References}

[1] E. F. Laine, "Remote monitoring of the steam-flood enhanced oil recovery process," Geophysics, vol. 52, no. 11, pp. 1457-1465, 1987.

[2] S. Bagci and M. V. Kok, "In-situ combustion laboratory studies of Turkish heavy oil reservoirs," Fuel Processing Technology, vol. 74, no. 2, pp. 65-79, 2001.

[3] R. M. Butler and D. J. Stephens, "The gravity drainage of steamheated heavy oil to parallel horizontal wells," Journal of Canadian Petroleum Technology, vol. 20, no. 2, pp. 90-96, 2013.

[4] S. Li, Z. Li, B. Li, and R. Lin, "Modeling of lifting heavy oil assisted by enclosed thermal fluid circulation in hollow rod," Journal of Petroleum Science and Engineering, vol. 75, no. 12, pp. 135-142, 2010.

[5] S. Y. Li, Z. M. Li, and B. F. Li, "Experimental study and application on profile control using high-temperature foam," Journal of Petroleum Science and Engineering, vol. 78, no. 3-4, pp. 567-574, 2011.

[6] S. Y. Li, Z. M. Li, and X. N. Sun, "Effect of flue gas and nhexane on heavy oil properties in steam flooding process," Fuel, vol. 187, pp. 84-93, 2017.

[7] S. Y. Li, Z. M. Li, and B. F. Li, "Experimental study and application of tannin foam for profile modification in cyclic steam stimulated well," Journal of Petroleum Science and Engineering, vol. 118, pp. 88-98, 2014.

[8] W. L. Kang, J. H. Li, and G. F. Liu, "Preparation and stability of simulated crude-oil emulsion," Journal of Northeast Normal University, vol. 37, no. 2, pp. 76-79, 2005. 
[9] C. L. Sun, W. L. Kang, W. D. Liu, and H. M. Xiao, "Studies on the factors affecting crude oil emulsion stability," Journal of Oil and Gas Technology, vol. 32, no. 2, pp. 134-137, 2010.

[10] J. Meng, Y. Xiang, X.-L. Wei, and S.-Y. Li, "High internal phase heavy oil water-oil emulsion rheology," Journal of Southwest Petroleum University, vol. 29, no. 2, pp. 122-124, 2007.

[11] C. Yuxiang, C. Jun, P. Chengsong, L. Gang, and X. Xiqing, "Influence of asphaltenes and resins on the stability of heavy crude emulsions," Applied Chemical Industry, vol. 38, no. 2, pp. 194-200, 2009.

[12] N. Lai, Q. Peng, Z. Ye, X. Song, and Y. Wen, "Influence of heavy components on the heavy oil emulsion stability," Journal of Southwest Petroleum University (Science \& Technology Edition), vol. 36, no. 1, pp. 145-149, 2014.

[13] J. Jiang, J. S. Li, C. X. Qi, X. Yin, and T. Chang, "Study on complex thermal fluids huff and puff technology in offshore heavy oil reservoir," Reservoir Evaluation and Development, vol. 2, no. 4, pp. 38-40, 2012.

[14] X. Qu, Z. Shan, H. Zong, H. Fang, and J. Zheng, "Effect of polymer on the stability of crude oil emulsions," Applied Chemical Industry, vol. 41, no. 7, pp. 1176-1178, 2012.

[15] M. Y. Li and Z. L. Wu, Petroleum Emulsion [M], Science Press, Beijing, 2009.

[16] M. Q. Lin, H. Wang, D. Tian, L. Mao, H. Zong, and M. Li, "Oilwater interfacial properties and emulsion stability of produced water from an oilfield with polymer-surfactant combination flooding," Petrochemical Technology, vol. 40, no. 7, pp. 753-758, 2011.

[17] W. Hang, M. Y. Li, M. Q. Lin, Z.-X. Dong, and J.-X. Guo, "Effect of interfacial properties of flooding with polymer and surfactant on the stability of emulsion," Petroleum Geology \& Oilfield Development in Daqing, vol. 26, no. 6, pp. 110-118, 2007.

[18] L.-Y. Qi, M.-R. Li, P.-Y. Gai, Y.-B. Cao, and P.-Z. Tang, "Stability of heavy crude water-in-oil emulsion characterizing by SV value," Oilfield Chemistry, vol. 30, no. 3, pp. 460-463, 2013.

[19] Y. L. Zhao, W. L. Kang, X. Xia et al., "Relationship between the stability of changqing water in oil emulsions and asphaltene content," Acta Petrolei Sinica, Petroleum Processing Section, vol. 34, no. 3, pp. 592-599, 2018.

[20] J. M. Bai, Study on the influence of heavy crude components and emulsifiers on the interfacial properties $[D]$, China University of Petroleum, 2009.

[21] R. A. Mohammed, A. I. Bailey, P. F. Luckham, and S. E. Taylor, "The effect of demulsifiers on the interfacial rheology and emulsion stability of water-in-crude oil emulsions," Colloids and Surfaces, vol. 91, no. 3, pp. 129-139, 1994.

[22] R. P. Borwankar, L. A. Lobo, and D. T. Wasan, "Emulsion stability - kinetics of flocculation and coalescence," Colloids and Surfaces A: Physicochemical and Engineering Aspects, vol. 69, no. 2-3, pp. 135-146, 1992.

[23] J. E. Emmanuel and J. A. Emmanuel, "A review of water-inheavy oil emulsion stability destabilization and interfacial rheology," Journal of Engineering and Applied Sciences, vol. 5, no. 6, pp. 447-452, 2010.

[24] A. Carlos da Silva Ramos, L. Haraguchi, F. R. Notrispe, W. Loh, and R. S. Mohamed, "Interfacial and colloidal behavior of asphaltenes obtained from Brazilian crude oils," Journal of Petroleum Science and Engineering, vol. 32, no. 2-4, pp. 201216, 2001.
[25] C. J. Morales, U. Riebel, N. M. Guzmán, and M. Guerra, "Formulation of water in paraffin emulsions," Latin American Applied Research, vol. 41, no. 2, 2011.

[26] H. Alboudwarej, M. Muhammad, A. K. Shahraki, S. Dubey, L. Vreenegoor, and J. M. Saleh, "Rheology of heavy-oil emulsions," SPE Production \& Operations, vol. 22, no. 3, pp. 285293, 2013.

[27] J. D. McLean and P. K. Kilpatrick, "Effects of asphaltene solvency on stability of water-in-crude-oil emulsions," Journal of Colloid and Interface Science, vol. 189, no. 2, pp. 242-253, 1997.

[28] N. Zaki, P. C. Schorling, and I. Rahimian, "Effect of asphaltene and resins on the stability of water-in-waxy oil emulsions," Petroleum Science and Technology, vol. 18, no. 7-8, pp. 945963, 2000.

[29] J. Zhang, D. Tian, M. Q. Lin, Z. Yang, and Z. Dong, "Effect of resins, waxes and asphaltenes on water-oil interfacial properties and emulsion stability," Colloids and Surfaces A: Physicochemical and Engineering Aspects, vol. 507, pp. 1-6, 2016.

[30] J. B. Liu, L. G. Zhong, X. N. Yuan et al., "Study on the reemulsification process of water in heavy oil emulsion with addition of water-soluble viscosity reducer solution," Energy \& Fuels, vol. 33, no. 11, pp. 10852-10860, 2019.

[31] C. Wang, L. G. Zhong, Z. J. Cao, Y. Liu, J. Zou, and Q. Wang, "Synergistic collaboration between a viscosity reducer and a surfactant for in situ emulsion formation to enhance heavyoil recovery," Energy \& Fuels, vol. 34, no. 1, pp. 95-102, 2019. 